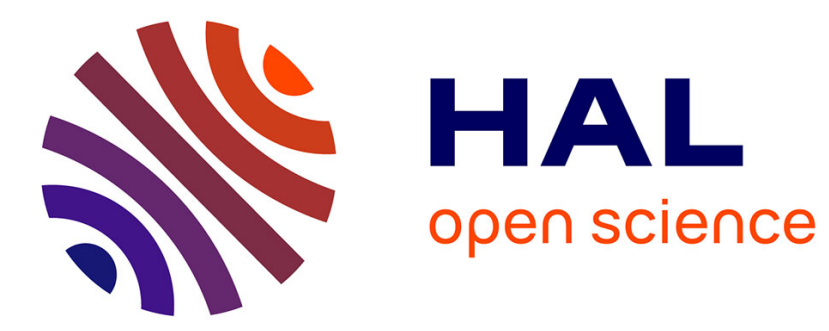

\title{
Morbidity and Mortality in Craniopharyngioma Patients after Surgery
}

Rachel K Crowley, Ole Petter Hamnvik, Eoin P O'Sullivan, Lucyann Behan, Diarmuid Smith, Amar Agha, Christopher J Thompson

\section{- To cite this version:}

Rachel K Crowley, Ole Petter Hamnvik, Eoin P O'Sullivan, Lucyann Behan, Diarmuid Smith, et al.. Morbidity and Mortality in Craniopharyngioma Patients after Surgery. Clinical Endocrinology, 2010, 10.1111/j.1365-2265.2010.03838.x . hal-00552614

\section{HAL Id: hal-00552614 https://hal.science/hal-00552614}

Submitted on 6 Jan 2011

HAL is a multi-disciplinary open access archive for the deposit and dissemination of scientific research documents, whether they are published or not. The documents may come from teaching and research institutions in France or abroad, or from public or private research centers.
L'archive ouverte pluridisciplinaire HAL, est destinée au dépôt et à la diffusion de documents scientifiques de niveau recherche, publiés ou non, émanant des établissements d'enseignement et de recherche français ou étrangers, des laboratoires publics ou privés. 


\section{CLINICAL ENDOCRINOLOGY}

\section{Morbidity and Mortality in Craniopharyngioma Patients after Surgery}

\begin{tabular}{|c|c|}
\hline Journal: & Clinical Endocrinology \\
\hline Manuscript ID: & CEN-2009-000833.R2 \\
\hline Manuscript Type/Office: & 1 Original Article - UK/Europe \\
\hline $\begin{array}{r}\text { Date Submitted by the } \\
\text { Author: }\end{array}$ & 04-May-2010 \\
\hline Complete List of Authors: & $\begin{array}{l}\text { Crowley, Rachel; Beaumont Hospital, Academic Department of } \\
\text { Endocrinology } \\
\text { Hamnvik, Ole Petter; Beaumont Hospital, Academic Department of } \\
\text { Endocrinology } \\
\text { O'Sullivan, Eoin P; Beaumont Hopsital, Academic Department of } \\
\text { Endocrinology } \\
\text { Behan, LucyAnn; Beaumont Hospital, Academic Department of } \\
\text { Endocrinology } \\
\text { Smith, Diarmuid; Beaumont Hospital, Academic Department of } \\
\text { Endocrinology } \\
\text { Agha, Amar; Beaumont Hospital, Academic Department of } \\
\text { Endocrinology } \\
\text { Thompson, Christopher J; Beaumont Hospital, Academic } \\
\text { Department of Endocrinology }\end{array}$ \\
\hline Key Words: & craniopharyngioma, hypopituitarism, mortality, obesity \\
\hline
\end{tabular}

\section{ScholarONE




\title{
Morbidity and Mortality in
}

\section{Craniopharyngioma Patients}

\section{after Surgery}

Short title: Morbidity and Mortality in

\author{
Craniopharyngioma
}

\author{
RK Crowley, OP Hamnvik, EP O’Sullivan, LA \\ Behan, D Smith, A Agha, CJ Thompson
}

Academic Department of Endocrinology, Beaumont Hospital, Dublin 9, Ireland

Correspondence: RK Crowley, Beaumont Hospital, Dublin 9, Ireland. rachelcrowley@hotmail.com

Keywords: craniopharyngioma, hypopituitarism, mortality, obesity 


\section{SUMMARY}

Objective: Craniopharyngioma (CP) is a benign tumour of the suprasellar region that is associated with increased morbidity and mortality in comparison to other causes of hypopituitarism. We aimed to establish the rate and causes of mortality and morbidity in patients with CP who attended our centre.

Design: We performed a retrospective case note audit of CP patients who were managed by our service. We established the Standardised Mortality Ratio for CP patients. We compared obesity prevalence with two other hypopituitary groups who are managed by our service.

Patients: We identified 70 patients with craniopharyngioma, $97 \%$ of whom had undergone surgery and $42 \%$ radiotherapy. We compared the prevalence of obesity with that of 89 patients with hypopituitarism secondary to surgery for non-functioning pituitary adenoma, and 29 patients with post-traumatic hypopituitarism.

Measurements: Standardised Mortality ratio for CP patients was $\mathbf{8 . 7 5}$ (95\% Cl of 5.4-13.3); SMR for women was $10.51(95 \% \mathrm{Cl} 5.04-19.3)$ and $7.55(95 \% \mathrm{Cl} 3.77-13.52)$ for men. The rates of $\mathrm{GH}$, gonadotrophin, ACTH and TSH deficiencies were $91 \%, 93.5 \%, 92 \%$ and $86 \%$, respectively. The rate of diabetes insipidus was $81 \% ; 7.1 \%$ had adipsic diabetes insipidus. Dyslipidaemia was present in $\mathbf{4 6 . 9 \%}$ and diabetes mellitus in $11.5 \%$. Obesity affected $66 \%$ of CP patients, $47 \%$ of non-functioning adenoma 
patients and $31 \%$ of those with post-traumatic hypopituitarism $(p<$ 0.001).

Conclusions: Patients with craniopharyngioma suffer from high rates of mortality and morbidity. The underlying causes for mortality and for obesity in this population remain poorly-understood.

Word count: 242 


\section{INTRODUCTION}

Craniopharyngioma (CP) is a benign tumour of the suprasellar region which has been associated with increased morbidity and mortality in comparison to other causes of hypopituitarism ${ }^{1-4}$. The increased mortality has been attributed to both cardiovascular and respiratory disease, but the reported susceptibility to cardiorespiratory disease is poorly understood. The reported morbidity associated with craniopharyngioma includes high rates of hypopituitarism, hypothalamic complications and impaired quality of life ${ }^{5}$.

The aim of this study was to establish mortality rates in CP patients treated at our institution and to calculate the Standardised Mortality Ratio (SMR). We also wished to document the spectrum of morbidity, and the potential contribution of co-morbidities, such as obesity, hypertension, dyslipidaemia and diabetes mellitus, to the increased mortality in CP. We compared the prevalence of obesity in our CP population to that of another patient cohort with tumoural hypopituitarism (non-functioning pituitary adenoma) and to that of a hypopituitary group of similar age (post-traumatic hypopituitarism), who were managed in the same centre. 


\section{METHODS}

Patients were identified from the hospital pituitary database, which collates details from all patients treated between 1980 and 2008.70 patients (39 male) with craniopharyngioma were identified from the database; 21 patients had died at the time of analysis.

Mortality

Patients who died while under follow-up in our hospital had cause of death identified from hospital casenotes and local post-mortem information. For patients who were lost to follow-up, or who were followed up in other institutions, the family practitioner was contacted in order to identify patients who had died.

Cause of death was established from death certificates from the Office of the Registrar General and from post mortem data. Mortality rates for the Irish population were obtained from the Central Statistics Office of Ireland. The background Irish mortality rate per 1000 population for each age group and gender was expressed as a decimal and converted into a cumulative mortality by summation of previous yearly mortality.

The expected mortality by age and gender of each craniopharyngioma patient was calculated:

Background cumulative mortality for year of death - Background cumulative mortality for the year of diagnosis with craniopharyngioma 
The craniopharyngioma Standardised Mortality Ratio (SMR) was defined as:

Number of deaths observed / number of expected deaths in an age- and gender-matched population

Irish data were available from the years 1950-2004; thus the background mortality in 2005 to 2008 was assumed to equal that of 2004 . Poisson probability distribution was used to calculate the $95 \%$ confidence interval (Cl) for the SMR.

Morbidity

Case note review was performed for collection of morbidity data and details were recorded in a spreadsheet (Windows Excel). Biographical details included gender, date of birth and age at diagnosis and death. Case management details included use of surgery and radiotherapy, surgical approach, recurrence of tumour, pituitary hormone replacement therapy and dosage and prescription of statin, anti-hypertensive and anti-epileptic therapy. Prevalence of anterior pituitary hormone deficiency and diabetes insipidus was recorded.

The most recent measurement of fasting blood glucose and lipid profile, and blood pressure, height, weight and BMI measurements from the most recent outpatient office measurement were noted. Historical 
diagnoses of diabetes mellitus, hypertension or dyslipidaemia were also recorded. The diagnosis of diabetes mellitus was based on standard WHO criteria of positive OGTT results, two fasting blood glucose concentrations $>7.0 \mathrm{mmol} / \mathrm{l}$ or a random blood glucose of $>11.1 \mathrm{mmol} / \mathrm{l}$ when accompanied by osmotic symptoms. Hypertension was diagnosed by three office readings of $>140 / 90 \mathrm{mmHg}$. Dyslipidaemia was defined as total cholesterol $>5 \mathrm{mmol} / \mathrm{l}$ or $\mathrm{LDL}$ cholesterol $>2.6$ $\mathrm{mmol} / \mathrm{l}$.

GH deficiency (GHD) was defined as a peak GH response of less than 3 $\mu \mathrm{g} / \mathrm{l}$ in response to insulin tolerance test (ITT) or glucagon stimulation test (GST), as defined by locally derived normative data ${ }^{6}$. ACTH deficiency was defined as a peak cortisol less than $500 \mathrm{nmol} / \mathrm{I}$ on ITT or $450 \mathrm{nmol} / \mathrm{l}$ on GST, as previously defined ${ }^{6}$. Gonadotrophin deficiency in pre-menopausal women was defined as amenorrhea for more than 6 months in the presence of low oestradiol and normal or low gonadotrophins. In post-menopausal women gonadotrophin deficiency was defined as gonadotrophins of pre-menopausal range. In men gonadotrophin deficiency was defined as symptomatic low testosterone, and inappropriately low gonadotrophins. TSH deficiency was defined as low T4 in the presence of low or normal TSH. Diabetes insipidus was diagnosed in the post-operative period by the presence of polyuria and hypernatraemia, according to the criteria of Seckl and Dunger ${ }^{7}$ and confirmed with water deprivation test six weeks after discharge. Adipsia was diagnosed by use of an infusion of hypertonic saline ( $855 \mathrm{mmol} / \mathrm{l})$ 
with measurement of thirst as previously described ${ }^{8}$. Prevalence of other morbidity such as obesity, hydrocephalus, seizures, visual loss and venous thrombosis was recorded from the case notes.

Body mass index (BMI) data were compared to that of other hypopituitary groups; 89 patients with hypopituitarism after surgery for non-functioning pituitary adenoma (NFPA) and 29 patients with hypopituitarism after traumatic brain injury (TBI), also identified from the pituitary database.

\section{Statistics}

Mean and standard deviation were used to describe data that were normally distributed; otherwise the median and range was reported. BMI data were compared with Wilcoxon's test and subanalysed with Tukey's HSD. Significance of subanalysis findings was determined by post hoc $\mathrm{t}$ test with correction for multiple comparisons. JMP 5 (SAS Institute, California, USA) was used for statistical analysis. The study was approved by the local Ethics Committee. 


\section{RESULTS}

\section{Mortality}

Median follow-up of craniopharyngioma patients from time of diagnosis was 8 years (range 1-50 years). Twenty-four patients (34\%) were diagnosed with CP in childhood. Twenty-one CP patient deaths were observed between 1988 and 2007. The expected mortality in this population was 2.4, therefore SMR was 8.75 with a $95 \% \mathrm{Cl}$ of 5.4-13.3. SMR for women (10.51, 95\% Cl 5.04-19.3) was higher than for men (7.55, 95\% Cl 3.77-13.52), but this was not statistically significant (RR $1.388, \mathrm{Cl}$ 0.55-3.51) ${ }^{9}$. Causes of death are reported in Table 1.

\section{Morbidity}

Age at diagnosis was distributed in a bimodal pattern (Fig 1). Sixtyeight patients underwent surgical intervention; 2 patients were diagnosed with CP on radiological appearance alone and did not undergo surgery because of preservation of visual fields. Eight patients underwent surgery by a trans-sphenoidal approach, 5 of which required a later craniotomy. An average of 60 pituitary resections were performed in the centre each year; there were eight neurosurgeons in the centre, 1 of whom was a specialist pituitary surgeon. Three successive pituitary surgeons were responsible for the service over the time period studied. 
Radiotherapy details were not available for 6 patients (4 deceased, 1 attended follow-up elsewhere, 1 failed to follow up). Of the remaining 64 patients, 27 (42\%) underwent radiotherapy; 16 after recurrence, 1 as prophylaxis with early recurrence and 10 of these patients received prophylactic radiotherapy without recurrence. Records were incomplete in 3 deceased patients; of the remaining 67,31 patients $(46.2 \%)$ suffered from tumour recurrence.

Growth hormone deficiency (GHD) was diagnosed in 53 of 58 patients (91\%) for whom the GH axis was tested; of the remaining 12 patients, 8 died prior to 1997 when assessment for adult GHD became routine in our unit and 4 did not follow-up with our service. Of those 5 patients considered to have intact GH secretion, 2 did not undergo surgery and the remaining 3 were considered to be GH replete because of a normal IGF1 result. Of the patients identified with GHD, $62 \%$ received GH replacement. GH was not replaced because of tumour mass or recurrence in $8 \%$ of GHD patients, discontinued after perceived lack of benefit in $16 \%$, discontinued after the development of diabetes in $5.4 \%$, or not commenced because of patient age (over 70 years) in $5.4 \%$. GH replacement therapy was monitored by serial measurement of IGF1 and titrated to maintain IGF1 in the upper half of the normal reference range. Median GH dose was $0.35 \mathrm{mg}$ with a range of $0.2-1.8 \mathrm{mg}$. Analysis of mortality in GHD patients who received replacement compared with those who did not, was not significant $\left(x^{2}, p=0.2\right)$. 
ACTH status was not documented in 4 patients; 3 were deceased and 1 attended another institution. Of those for whom data was available, 61 patients (92\%) had ACTH deficiency. 2 of the patients with intact ACTH secretion had not undergone surgery, 2 failed to follow-up with our service and 1 was managed elsewhere. All patients diagnosed with ACTH deficiency received replacement therapy with hydrocortisone or prednisolone. Median daily dose of steroid was equivalent to $20 \mathrm{mg}$ of hydrocortisone, range $10-30 \mathrm{mg}$, where $5 \mathrm{mg}$ prednisolone was considered equivalent to $20 \mathrm{mg}$ of hydrocortisone.

Gonadotrophin status was not assessed in 1 paediatric patient, not documented for 5 deceased patients and unknown in 2 patients who did not follow-up in our institution. Of those for whom data was available, 58 patients (93.5\%) were deficient. Gonadotrophin deficiency was treated with sex hormone replacement in all men and in women who were younger than 51 years of age at the time of diagnosis.

Thyrotrophin (TSH) status was not documented for 1 patient who attended another institution and for 4 deceased patients. Of the remaining patients, 56 (86\%) were TSH deficient. All patients with TSH deficiency received replacement therapy with thyroxine. Median daily dose was $112 \mu \mathrm{g}$ of thyroxine, range $50-250 \mu \mathrm{g}$.

Diabetes insipidus (DI) was documented in 56 patients (81\%), who all received replacement desmopressin (dDAVP) therapy. Median dDAVP 
dosage was twice per day, with a range of nil to 6 doses per day.

Patients were advised to miss one dose at the weekend in order to avoid fluid overload. Four patients $(7.1 \%)$ had adipsic diabetes insipidus.

Lipid profile and blood pressure were recorded after appropriate hormone replacement therapy. Median total cholesterol was $5.0 \mathrm{mmol} / \mathrm{l}$, with a range of $3.3-8.2 \mathrm{mmol} / \mathrm{l}$ (target reference range $<5 \mathrm{mmol} / \mathrm{l}$ ). Median LDL cholesterol was $3.2 \mathrm{mmol} / \mathrm{l}$, with a range of $1.1-5.2 \mathrm{mmol} / \mathrm{l}$ (target < $2.6 \mathrm{mmol} / \mathrm{l}$ ), HDL was $1.1 \mathrm{mmol} / \mathrm{l}$ (range $0.6-2.8 \mathrm{mmol} / \mathrm{l}$, target $>1 \mathrm{mmol} / \mathrm{l}$ ) and triglyceride was $2.2 \mathrm{mmol} / \mathrm{l}$ (range $0.6-6.7 \mathrm{mmol} / \mathrm{l}$, target $<1.9 \mathrm{mmol} / \mathrm{l})$. Twenty-three patients of the 49 survivors (46.9\%) had total cholesterol of more than $5 \mathrm{mmol} / \mathrm{l}$, of whom only 11 were known to be on a statin. There was no difference between CP patients who died and those who continued to attend the outpatients in any lipid parameter.

Five of the surviving 49 patients had a blood pressure of equal to or greater than $140 / 90 \mathrm{mmHg}, 2$ of whom were treated with antihypertensives. One other patient had achieved normal blood pressure with an ACE inhibitor. Ten patients of historically normal blood pressure were followed up elsewhere. Current data therefore suggests that $6 / 39(15.3 \%)$ have hypertension.

Six patients out of $\mathbf{5 2}$ for whom results were available were had diabetes mellitus (11.5\%); 1 was diagnosed with Type 1 diabetes in childhood 
prior to the diagnosis of CP. Median fasting glucose was $4.8 \mathrm{mmol} / \mathrm{l}$ (range $2.3-11 \mathrm{mmol} / \mathrm{l}$ ).

Median BMI in CP patients was $31.8 \mathrm{~kg} / \mathrm{m}^{2}$ (range $20.3-61.2 \mathrm{~kg} / \mathrm{m}^{2}$ ). $66 \%$ of CP patients had a BMl in the obese range (greater than $30 \mathrm{~kg} / \mathrm{m}^{2}$ ) and $26 \%$ were overweight (BMI $25-29.9 \mathrm{~kg} / \mathrm{m}^{2}$ ). The CP patients were compared to two other hypopituitary cohorts identified from the local database: non-functioning adenoma patients (NFPA; median BMI 29.8, 47\% obese) and those with post-traumatic hypopituitarism (PTHP; median BMI 26.6, $31 \%$ obese). There was a significant difference in BMI across the three groups (Figure 2 and Table 2, $p<0.001$, Wilcoxon). Subanalysis revealed that there was no difference between the BMI of CP and NFPA patients (Tukey HSD) but there was a difference between both CP and NFPA patients compared to PTHP patients. Student $t$ test with correction for multiple comparisons revealed no significant difference between CP and NFPA BMI, but a significant difference between CP and PTHP $(p<0.001)$ and between NFPA and PTHP $(p<$ 0.05). There was also a significant difference in age between the groups (Table 2).

Hydrocephalus was documented radiologically in $40.3 \%$ of patients, and was more prevalent in patients who were deceased at the time of analysis than in live patients (chi square, $p<0.0001$ ). Seizures affected $49 \%$ of patients and were associated with hydrocephalus (chi square, $p$ 
$<0.0001$ ). Seventy-seven percent of patients had documented visual field loss.

Seven patients had a history of development of either a deep venous thrombus (DVT) or a pulmonary embolus (PE). Post-mortem studies revealed that PE was the cause of death in 2 / 21 deceased patients (Table 1). 


\section{DISCUSSION}

Craniopharyngioma (CP) is a tumour with a higher mortality than pituitary adenomata that is not explained by endocrine morbidity alone. Our management of craniopharyngioma is comparable to that in other tertiary centres, thus our findings are representative of the wider experience with CP. The elevated SMR for CP in our centre (8.75) is comparable to that of published international studies. In an analysis of the West Midlands database reported by Tomlinson et al, the SMR was 9.28 in craniopharyngioma patients ${ }^{2}$, an excess mortality which was mainly attributed to respiratory and cardiovascular disease. A singlecentre Swedish study, which analysed mortality in 60 CP patients, and which documented an elevated SMR of $5.5^{3}$, reported that 7 of 27 deaths were related to pneumonia or PE. Our single-centre study also documents an excess of deaths due to respiratory disease. There is a consistent reporting of excess respiratory and vascular disease in the available literature. Because this was a retrospective study, we were forced to depend on the accuracy of death certificate reports, the majority of which were completed in hospitals other than our own. In Ireland, physicians are legally required to report cause rather than mechanism of death. Knowledge of the mechanism of death, such as respiratory failure, would have been of greater clinical value in assessment of mortality. For instance, our clinical suspicion is that some of the deaths were attributable to respiratory failure due to documented severe obstructive sleep apnoea. 
The authors of both the UK and the Swedish studies suggested that untreated GH deficiency contributed to the excess mortality of hypopituitary patients. There are confounding factors in their studies that should be considered, however, when analysing whether their data fully substantiates this suggestion. Both series included patients diagnosed prior to the use of dynamic testing for GHD in adults, which questions the accuracy of diagnosis of GH deficiency in some patients. In addition, early post-operative deaths, prior to testing for GH deficiency may have led to under-estimation of the rate of GHD. We have a policy of offering GH replacement to all eligible GHD adults with craniopharyngioma, which differs slightly from historical practice in the West Midlands centre; our data did not show any survival benefit of GH treatment compared with those who were not treated. Larger studies, with multicentre cooperation would probably be required to answer this question.

Female patients with hypopituitarism due to any cause have a higher mortality than their male counterparts ${ }^{2,3,10}$. Our data suggested a trend in this direction, though the relative risk of death for women compared to men did not reach statistical significance. This is likely to reflect the small absolute numbers of deaths involved in our series. It has been speculated that sub-optimal sex steroid replacement in women may contribute to this reversal of gender mortality when compared to the background population, and the Swedish group have suggested that the pre-diagnosis clinical history of oestrogen deficiency should be 
included in the total time of oestrogen deficiency in order to give some indication of increased cardiovascular risk ${ }^{10,11}$. We would observe, however, that one of our patients, who subsequently died of respiratory failure, developed multiple pulmonary emboli on oestrogen replacement, during an episode of hypernatraemic dehydration due to adipsic diabetes insipidus. Hormonal treatment is not always straightforward, therefore, in this group of patients.

The excess mortality in CP patients may be related to hypothalamic damage and its complications, such as adipsic DI ${ }^{12}$ and obesity ${ }^{2,10,13,}$ 14. A recent, single centre study in Holland reported an elevated SMR of 2.88 in 54 CP patients, with higher rates of obesity and diabetes than the background Dutch population ${ }^{10}$. Obesity is a recognised complication of CP and also of the effects of treatment of CP, with surgery and radiotherapy ${ }^{15-17}$. We report a very high prevalence of CP obesity (66\%) in our CP cohort compared to the prevalence in Irish people of $18 \%{ }^{18}$. We expected a high rate of obesity in our CP cohort, but were surprised by the high incidence of obesity in our NFPA cohort, which was not statistically different to that in CP. The NFPA group was significantly older than the CP cohort, and as age is an independent associate of obesity, we compared the rates of obesity in CP to age-matched patients with hypopituitarism secondary to brain trauma; our data showed a considerable excess of obesity in the groups with tumoural hypopituitarism. Patients with PTHP appear to suffer from significantly less obesity than patients with tumoural hypopituitarism, but they have 
a much shorter duration of follow-up because PTHP has been recognised relatively recently. The excess of obesity in the younger CP group is clinically very relevant, as obesity in a younger population predicts a higher risk of future morbidity and mortality. Obesity has been suggested, for instance, to contribute to cardiovascular mortality in $\mathrm{CP}^{10}$. We have reported deaths due to sleep apnoea in CP patients ${ }^{12}$, and the possible contribution of obesity-related sleep apnoea to respiratory mortality in CP patients deserves formal study.

Neurosurgical intervention in CP is often performed before full preoperative endocrine assessment ${ }^{3}$. Thus we cannot comment on the relative effects of pre-operative $\mathrm{CP}$ tumour bulk and surgical intervention on pituitary function. The 3 patients who were assessed before the adoption in 1997 of formal dynamic testing for GH deficiency, and who were considered to have adequate GH secretion on the basis of a normal IGF1 result, would probably have failed GH stimulation testing, given that they had evidence of deficiency of all other pituitary hormones ${ }^{19}$. The true rate of GHD in our CP cohort is therefore more likely to be $96 \%$. GH, gonadotrophin and TSH deficiencies in our cohort were comparable to international reports ${ }^{10,20}$. ACTH deficiency has been reported to range from 55 to $88 \%$ in a review of the literature by Karavitaki, but our prevalence figures were a little higher at $92 \%$.

Craniotomy is a frequently used surgical approach for management of craniopharyngioma, particularly in cases of large tumour size and 
suprasellar location ${ }^{15,20,21}$. Our use of the craniotomy approach is at the higher end of international practice and might have contributed to the high rates of hypopituitarism and hypothalamic complications reported in our cohort. Gross total resection is rarely achieved in CP patients, and where surgical clearance is attempted, imaging studies can reveal a remnant in $18-26 \%$ of cases ${ }^{20}$. Thus a more conservative surgical debulking procedure followed by irradiation of the remnant is currently favoured in the hope that this approach might be less destructive to hypothalamic and pituitary function. In our centre, radiotherapy was used both for prevention of recurrence and as a therapeutic intervention for recurrence. In spite of our local practice to attempt gross total resection, recurrence rate $(46 \%)$ was comparable to previous studies ${ }^{20}$.

Craniopharyngioma patients are at increased cardiac and cerebrovascular risk. Our cardiovascular risk assessment policy identified significant dyslipidaemia. The low rate of statin prescription probably reflects the youth of the CP population. A recent analysis of Irish cardiovascular mortality since the 1980 s attributed $30 \%$ of improvement in survival to a $4.6 \%$ decrease in the population total cholesterol $^{22}$, which suggests that our Irish CP cohort could benefit from more aggressive management of dyslipidaemia. Hypertension does not appear to be as prevalent a cardiovascular risk factor in the $\mathrm{CP}$ group, but the rate of diabetes $(11.5 \%)$ is much higher than that of the background Irish population $(4.8 \%)^{23}$. The majority of measurements of 
fasting glucose were recorded at baseline of pituitary stimulation testing, prior to hormone replacement. The true rate of diabetes mellitus may be higher because $\mathrm{GH}$ and glucocorticoids are known to affect glucose metabolism ${ }^{24,25}$, hence measurement of fasting glucose after hormone replacement may be a more appropriate evaluation. Given the spectrum of cardiorespiratory disease in CP, it may be valuable to adopt a formal screening programme for vascular risk factors such as diabetes mellitus, hypertension and hyperlipidaemia, and a more aggressive treatment schedule.

Frequent visual field loss and hydrocephalus reflected the large size of the tumours. The prevalence of seizures in our patient cohort was closely correlated with hydrocephalus and was higher than the rate of seizure in Oxford CP patients, which reported a $26 \%$ probability of seizure over 20 years of follow-up ${ }^{16}$. Hydrocephalus was more prevalent in patients who subsequently died, but not in patients diagnosed in childhood; this data from our study is a novel finding which deserves further study ${ }^{20}$.

CP patients are recognised to suffer high rates of $\mathrm{DI}^{8}$. DI patients are prone to the development of dehydration, volume contraction and hypernatraemia if they omit dDAVP replacement therapy or have limited access to fluid. Hypernatraemic dehydration increases the risk of thrombosis; this complication is particularly common in patients with adipsic DI, in whom we have described an increased frequency of 
thrombotic disease ${ }^{12}$. We recommend treatment of patients with adipsic DI with low molecular weight heparin prophylaxis during hypernatraemic episodes ${ }^{12}$ and this intervention for DI patients with intact thirst might have averted two of the deaths from pulmonary embolus in this cohort. Adipsic Dl is a well recognised, but not a common complication of CP; in a series of 13 patients with ADI, 4 had a diagnosis of $\mathrm{CP}$, which reflected the destructive effect of tumour bulk and surgery on the hypothalamus ${ }^{12,26}$. As adipsic DI is recognised to confer increased likelihood of premature death, and one of the young deaths in this cohort was attributable to complications of adipsic DI, we feel that this is a significant marker for increased morbidity and mortality in CP. 


\section{CONCLUSION}

We have shown that mortality is increased in an Irish CP population and that women are more affected than male patients. In our cohort increased mortality was not related to GH deficiency, or replacement, but was associated with a diagnosis of hydrocephalus, a probable marker of tumour size. There was a high rate of respiratory mortality, comparable to that previously published. The cause for increased mortality in CP patients is likely to be multifactorial, and includes excess hypothalamic morbidity, the high rate of obesity, hypopituitarism and adipsic diabetes insipidus. We did not find evidence for inappropriate hormone replacement therapy as a cause of morbidity or mortality in this study.

Strategies aimed at reducing mortality in $\mathrm{CP}$ are therefore only likely to be successful if they include a multifactorial approach, including preservation of hypothalamic structures at surgery, aggressive management of obesity and cardiovascular parameters, and management aimed at reducing the dangerous effects of sleep disturbance and adipsic diabetes insipidus.

Our study results confirm the high morbidity and mortality associated with a diagnosis of craniopharyngioma. 


\section{Acknowledgements}

The authors wish to acknowledge the assistance of G O'Connor, actuary, for calculation of Standardised Mortality Ratio.

Dr Rachel Crowley is the beneficiary of an unrestricted educational grant from Novo Nordisk. 


\section{References}

1 Dekkers, O.M., Biermasz, N.R., Smit, J.W., Groot, L.E., Roelfsema, F., Romijn, J.A. \& Pereira, A.M. (2006) Quality of life in treated adult craniopharyngioma patients. Eur J Endocrinol 154, 483-489.

2 Tomlinson, J.W., Holden, N., Hills, R.K., Wheatley, K., Clayton, R.N., Bates, A.S., Sheppard, M.C. \& Stewart, P.M. (2001) Association between premature mortality and hypopituitarism. West Midlands Prospective Hypopituitary Study Group. Lancet 357, 425-431.

3 Bulow, B., Attewell, R., Hagmar, L., Malmstrom, P., Nordstrom, C.H. \& Erfurth, E.M. (1998) Postoperative prognosis in craniopharyngioma with respect to cardiovascular mortality, survival, and tumor recurrence. J Clin Endocrinol Metab 83, 3897-3904.

4 DeVile, C.J., Grant, D.B., Hayward, R.D. \& Stanhope, R. (1996) Growth and endocrine sequelae of craniopharyngioma. Arch Dis Child 75, $108-114$.

5 Poretti, A., Grotzer, M.A., Ribi, K., Schonle, E. \& Boltshauser, E. (2004) Outcome of craniopharyngioma in children: long-term complications and quality of life. Dev Med Child Neurol 46, 220-229.

6 Agha, A., Rogers, B., Mylotte, D., Taleb, F., Tormey, W., Phillips, J. \& Thompson, C.J. (2004) Neuroendocrine dysfunction in the acute phase of traumatic brain injury. Clinical Endocrinology 60, 584-591.

7 Seckl, J. \& Dunger, D. (1989) Postoperative diabetes insipidus. BMJ 298, 2-3.

8 Smith, D., Finucane, F., Phillips, J., Baylis, P.H., Finucane, J., Tormey, W. \& Thompson, C.J. (2004) Abnormal regulation of thirst and 
vasopressin secretion following surgery for craniopharyngioma. Clin Endocrinol (Oxf) 61, 273-279.

9 Altman, D.G. \& Bland, J.M. (2003) Interaction revisited: the difference between two estimates. British Medical Journal 326, 219. 10 Pereira, A.M., Schmid, E.M., Schutte, P.J., Voormolen, J.H., Biermasz, N.R., van Thiel, S.W., Corssmit, E.P., Smit, J.W., Roelfsema, F. \& Romijn, J.A. (2005) High prevalence of long-term cardiovascular, neurological and psychosocial morbidity after treatment for craniopharyngioma. Clin Endocrinol (Oxf) 62, 197-204.

11 Erfurth, E.M., Bulow, B., Svahn-Tapper, G., Norrving, B., Odh, K., Mikoczy, Z., Bjork, J. \& Hagmar, L. (2002) Risk factors for cerebrovascular deaths in patients operated and irradiated for pituitary tumours. J Clin Endocrinol Metab 87, 4892-4899.

12 Crowley, R.K., Sherlock, M., Agha, A., Smith, D. \& Thompson, C.J. (2007) Clinical insights into adipsic diabetes insipidus: a large case series. Clin Endocrinol (Oxf) 66, 475-482.

13 Daousi, C., Dunn, A.J., Foy, P.M., MacFarlane, I.A. \& Pinkney, J.H. (2005) Endocrine and neuroanatomic features associated with weight gain and obesity in adult patients with hypothalamic damage. Am J Med 118, 45-50.

14 de Vile, C.J., Grant, D.B., Hayward, R.D., Kendall, B.E., Neville, B.G. \& Stanhope, R. (1996) Obesity in childhood craniopharyngioma: relation to post-operative hypothalamic damage shown by magnetic resonance imaging. J Clin Endocrinol Metab 81, 2734-2737. 
15 Verhelst, J., Kendall-Taylor, P., Erfurth, E.M., Price, D.A., Geffner,

M., Koltowska-Haggstrom, M., Jonsson, P.J., Wilton, P. \& Abs, R. (2005)

Baseline characteristics and response to 2 years of growth hormone (GH) replacement of hypopituitary patients with GH deficiency due to adult-onset craniopharyngioma in comparison with patients with nonfunctioning pituitary adenoma: data from KIMS (Pfizer International Metabolic Database). J Clin Endocrinol Metab 90, 4636-4643.

16 Karavitaki, N., Brufani, C., Warner, J.T., Adams, C.B., Richards, P., Ansorge, O., Shine, B., Turner, H.E. \& Wass, J.A. (2005)

Craniopharyngiomas in children and adults: systematic analysis of 121 cases with long-term follow-up. Clin Endocrinol (Oxf) 62, 397-409.

17 Pinkney, J., Wilding, J., Williams, G. \& MacFarlane, I. (2002) Hypothalamic obesity in humans: what do we know and what can be done? Obes Rev 3, 27-34.

18 (2005) Obesity: the Policy Challenges - The report of the National Taskforce on Obesity. Irish Department of Health and Children.

19 Toogood, A.A., Beardwell, C.G. \& Shalet, S.M. (1994) The severity of growth hormone deficiency in adults with pituitary disease is related to the degree of hypopituitarism. Clin Endocrinol (Oxf) 41, 511-516.

20 Karavitaki, N., Cudlip, S., Adams, C.B. \& Wass, J.A. (2006)

Craniopharyngiomas. Endocr Rev 27, 371-397.

21 Kendall-Taylor, P., Jonsson, P.J., Abs, R., Erfurth, E.M., Koltowska-Haggstrom, M., Price, D.A. \& Verhelst, J. (2005) The clinical, metabolic and endocrine features and the quality of life in adults with 
childhood-onset craniopharyngioma compared with adult-onset craniopharyngioma. Eur J Endocrinol 152, 557-567.

22 Bennett, K., Kabir, Z., Unal, B., Shelley, E., Critchley, J., Perry, I., Feely, J. \& Capewell, S. (2006) Explaining the recent decrease in coronary heary disease mortality rates in Ireland, 1985-2000. J Epidemiol Community Health 60, 322-327.

23 The Institute of Public Health in Ireland (2006) Making Diabetes Count, a systematic approach to estimating population prevalence on the island of Ireland in 2005. The Institute of Public Health in Ireland, Belfast.

24 Gathercole, L.L., Bujalska, I.J., Stewart, P.M. \& Tomlinson, J.W. (2007) Glucocorticoid modulation of insulin signalling in human subcutaneous adipose tissue. Journal of Clinical Endocrinology and Metabolism 92, 4332-4339.

25 Jorgensen, J.O., Moller, L., Krag, M., Billestrup, N. \& Christiansen, J.S. (2007) Effects of growth hormone and fat metabolism in human subjects. Endocrinol Metab Clin North Am 36, 75-87.

26 Smith, D., McKenna, K., Moore, K., Tormey, W., Finucane, J., Phillips, J., Baylis, P. \& Thompson, C.J. (2002) Baroregulation of vasopressin release in adipsic diabetes insipidus. J Clin Endocrinol Metab 87, 4564-4568. 


\section{TABLES}

\begin{tabular}{|c|c|c|c|c|}
\hline Patient & Gender & $\frac{\frac{\text { Age at }}{\text { Diagnosis }}}{\underline{C P}}$ & $\frac{\text { Age at }}{\text { death }}$ & Cause of Death \\
\hline 1 & $F$ & $\overline{64}$ & 71 & Myocardial infarction \\
\hline 2 & $\mathrm{~F}$ & 48 & 51 & $\mathrm{CP}$ \\
\hline 3 & $\mathrm{~F}$ & 74 & 81 & Respiratory arrest \\
\hline 4 & $\mathrm{M}$ & 47 & 49 & Respiratory arrest \\
\hline 5 & $\mathrm{M}$ & 63 & 68 & Not reported \\
\hline 6 & $\mathrm{M}$ & 26 & 61 & Epilepsy \\
\hline 7 & $\mathrm{M}$ & 34 & 38 & Metastatic Lung Carcinoma \\
\hline 8 & $\mathrm{~F}$ & 52 & 58 & Small cell lung carcinoma \\
\hline 9 & $F$ & 30 & 32 & Pulmonary Embolus \\
\hline 10 & $\mathrm{~F}$ & 66 & 68 & Respiratory Tract Infection \\
\hline 11 & $\mathrm{M}$ & 70 & 82 & Cerebral Thrombus \\
\hline 12 & $\mathrm{M}$ & 36 & 45 & Aspiration Pneumonia \\
\hline 13 & $\mathrm{M}$ & 43 & 43 & Cerebral Infarct \\
\hline 14 & $\mathrm{~F}$ & 44 & 46 & $\mathrm{CP}$ \\
\hline 15 & $\mathrm{~F}$ & 39 & 40 & $\mathrm{CP}$ \\
\hline 16 & $\mathrm{M}$ & 3 & 8 & Pneumonia \\
\hline 17 & $\mathrm{~F}$ & 16 & 23 & $\begin{array}{l}\text { Increased Intracranial } \\
\text { pressure }\end{array}$ \\
\hline 18 & $\mathrm{~F}$ & 13 & 13 & Pulmonary Embolus \\
\hline 19 & $\mathrm{M}$ & 7 & 19 & Glioma \\
\hline 20 & $\mathrm{M}$ & 48 & 53 & Left ventricular failure \\
\hline 21 & $\mathrm{M}$ & 11 & 20 & $\begin{array}{l}\text { Head trauma secondary to } \\
\text { seizure }\end{array}$ \\
\hline
\end{tabular}

Table 1. Mortality data of 21 craniopharyngioma patients. $F=$ female, $M=$ male, $\mathrm{CP}=$ craniopharyngioma. Cause of death reported as stated on death certificate (not located for patient 5). 


\begin{tabular}{|c|c|c|c|c|}
\hline Diagnosis & $\underline{\mathrm{n}}$ & $\frac{\text { Median Age }}{\text { years }}$ & $\frac{\text { Median BMI }}{\underline{\mathrm{kg} / \mathrm{m}^{2}}}$ & $\frac{\% \mathrm{BMI}>30}{\underline{\mathrm{kg} / \mathrm{m}^{2}}}$ \\
\hline CP & 70 & 27.5 & 31.7 & 66 \\
\hline NFPA & 89 & 52 & 29.8 & 47 \\
\hline PTHP & 29 & 41 & 26.6 & 31 \\
\hline p value & & $<0.001$ & $<0.001$ & \\
\hline
\end{tabular}

Table 2. Comparison of CP patients to NFPA and PTHP groups. Age at diagnosis is different for NFPA group from both CP and PTHP group.

Difference between CP and PTHP group is borderline non-signficant $(p=$ 0.052). BMI is different in PTHP group from both CP and NFPA. 


\section{Figures}

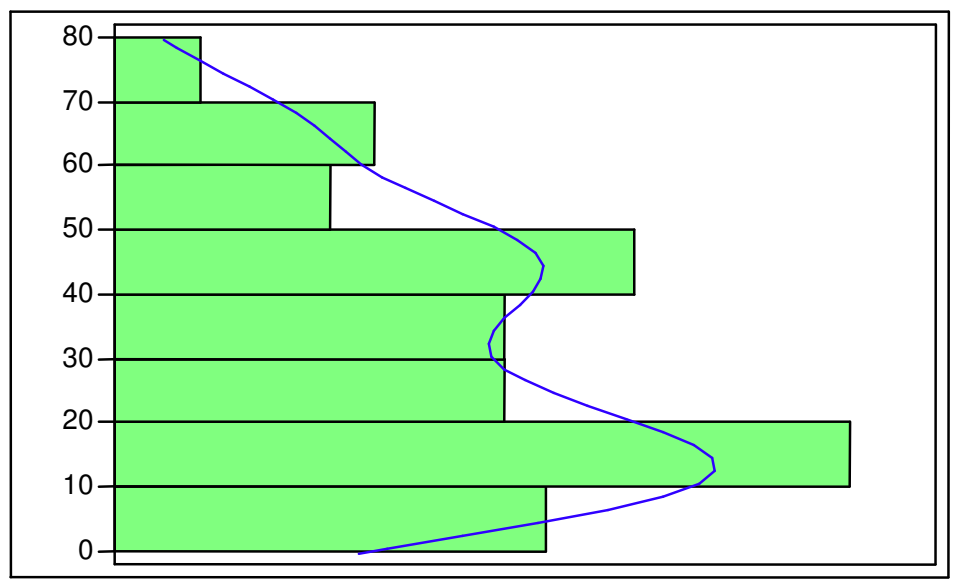

Figure 1. Distribution of CP patients by age at diagnosis. Line shows bimodal distribution

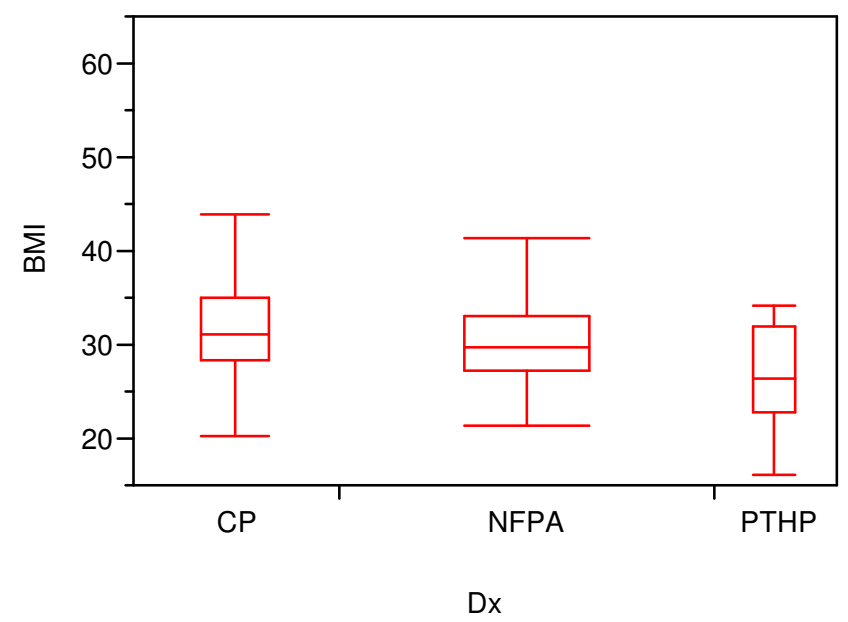

Figure 2. Comparison of BMI in Hypopituitary patients by underlying cause of hypopituitarism. CP = craniopharyngioma $(n=70)$, NFPA = nonfunctioning adenoma (89), PTHP = post-traumatic hypopituitarism (n = 29). 